\title{
EL FERROCARRIL BAEZA-UTIEL. CRÓNICA DE UN FRACASO COLECTIVO
}

\author{
Eduardo Araque Jiménez \\ Área de Análisis Regional. Universidad de Jaén \\ earaque@ujaen.es
}

\section{RESUMEN}

El ferrocarril Baeza-Utiel, concebido como una línea alternativa a las radiales que partían de Madrid, se planteó por primera vez a mediados del siglo XIX, pero no fue hasta 1926 cuando se aprobó oficialmente su construcción, después de que lo reclamaran con ahínco las "fuerzas vivas" y el grueso de la sociedad de las provincias de Jaén y Albacete. Tras ejecutarse el trazado en su mayor parte, e incluso dejar una parte preparado para su entrada en funcionamiento, las obras de la línea se paralizaron a principios de los años sesenta y se abandonaron definitivamente a comienzos de los años ochenta. De este modo se ponía fin a una línea ferroviaria que había generado grandes expectativas de cara al desarrollo de una de las zonas más deprimidas del interior de España. Una vez más los poderes públicos primaban los aspectos económicos y se mostraban insensibles ante una situación social y territorial marcada por el empobrecimiento y el aislamiento extremo de sus habitantes, a los que únicamente se dejaba abierta la puerta de la emigración definitiva.

Palabras clave: Ferrocarril Baeza-Utiel, Jaén, Albacete, Alternativa al trazado radial

\section{ABSTRACT}

\section{The railway from Baeza to Utiel. Chronicle of a collective failure.}

The railway from Baeza to Utiel, conceived like an alternative route to the radial lines that departed from Madrid, was initially outlined in the middle of XIXth Century. However, its construction was finally approved in 1926, after the most important people and the greater part of society from the provinces of Jaén and Albacete claimed for it. After the most part of railway was built, and the start-up of a stretch of it was prepared, the works were paralyzed in the early seventies and permanently abandoned in the early eighties. So, this railway, that had generated great expectations for the development of one of the poorest regions of the inland area of Spain, was closed. One more time, the Administration give priority to the economic aspects and was insensitive in front of the social and territorial situation, troubled by the poverty and extreme isolation of their inhabitants, which only had the definitive emigration like their unique possibility.

Keywords: Railway from Baeza to Utiel, Jaén, Albacete, alternative radial route.

\section{INTRODUCCIÓN}

A mediados de 2011 hacía pública mi opinión sobre el fiasco monumental que suponía el abandono anunciado del tranvía de Jaén ${ }^{1}$; una obra pública de cierta espectacularidad en la que se habían invertido 120 millones de euros y que había entrado en funcionamiento en fase de pruebas durante unos días, pero que con el cambio de gobierno municipal había decidido paralizarse sin entrar siquiera en servicio; situación en la que continua al día de hoy. Además de señalar algunos de los errores cometidos en el proceso

1 Véase Ideal (edición Jaén). 9 de julio de 2011; también en Jaén, ciudad habitable. 25 de julio de 2011. 
de diseño de la línea tranviaria, y de llamar la atención sobre la oportunidad de este medio de transporte público en un período de agudo encarecimiento del precio del petróleo y de colapso de la ciudad por el transporte privado, rechazaba la tozudez política, inadmisible en una provincia donde ya contábamos con algunos ejemplos verdaderamente sangrantes de abandono ferroviario, entre ellos el del vergonzoso ferrocarril Baeza-Utiel; un fracaso colectivo producto a partes iguales de la incuria de los gobernantes y de la permanente pasividad de una sociedad amedrentada, incapaz de revelarse ante las injusticias más flagrantes.

En efecto, esta línea férrea, concebida para conectar el valle del Guadalquivir con la región levantina, siguiendo un itinerario alternativo al que se había establecido a mediados del siglo XIX por el paso de Despeñaperros, cuando ya se encontraba prácticamente concluida, a falta sólo del balasto y del tendido de los raíles en una parte de su recorrido, se paralizó primero, y abandonó definitivamente poco tiempo después. Así se frustraron, una vez más, las esperanzas de cuantos habían visto en este proyecto ferroviario un medio para sortear el aislamiento secular y contribuir al desarrollo socioeconómico de uno de los ámbitos geográficos peninsulares más deprimidos y desatendidos durante siglos; una frustración que resultaba tanto más dolorosa y escandalosa por lo que suponía de despilfarro de unos fondos públicos que generosamente se habían puesto a disposición del ferrocarril en forma de una infraestructura de enorme envergadura en la cual se habían invertido varios miles de millones de pesetas. Todo ese esfuerzo de las arcas públicas acabó tirándose por la borda en un país y en unas provincias como las de Jaén y Albacete, donde las gravísimas carencias materiales de todo tipo aconsejaban, precisamente, todo lo contrario.

En las páginas que siguen trataremos de desentrañar el origen del ferrocarril Baeza-Utiel, así como las sucesivas etapas de su proceso de implantación, que arranca tras la instauración de la dictadura de Primo de Rivera y se extiende hasta los primeros años de gobierno del Partido Socialista Obrero Español (PSOE), en las postrimerías del siglo XX. Después de haber reclamado con insistencia a los distintos gobiernos de la Unión de Centro Democrático (UCD) la reapertura de la línea, cuando accedieron al poder los socialistas variaron radicalmente la postura política que habían mantenido mientras se hallaban en la oposición. Una vez en el gobierno los socialistas decidieron abandonarla definitivamente y proceder al desmantelamiento y enajenación de todas sus instalaciones, poniendo así punto final a una larga historia plagada de sinsentidos y contradicciones.

\section{ANTECEDENTES Y APROBACIÓN DE LA LÍNEA}

La primera referencia que tenemos sobre un trazado similar al que luego seguiría la línea Baeza-Utiel, aunque algo menos extenso, la encontramos en el proyecto sobre ferrocarriles de Francisco Coello, hecho público en el momento en que empezaba a alborear el ferrocarril en España (Coello, 1855). Este geógrafo nacido en Jaén, concibió un plan de establecimiento ferroviario que alternaba el diseño radial, preponderante hasta entonces, con un trazado de líneas transversales, mucho mejor adaptadas a las condiciones topográficas de la Península Ibérica, cuya principal ventaja radicaba en la posibilidad de poder enlazar las costas atlántica y mediterránea (Vidal Raich, 1994). Desde su presentación, poco más se supo de este trazado hasta que a finales del siglo XIX una serie de particulares solicitaron autorización para el establecimiento de varios ferrocarriles de distinto ancho y diferente longitud que trataban de enlazar el valle del Guadalimar con la comarca de La Loma, o bien la Sierra de Segura con tierras manchegas, pero todos ellos acabaron desistiendo de llevar a cabo las obras (Casado y González, 1984).

El primer precedente claro del ferrocarril Baeza-Utiel lo encontramos en el Plan de ferrocarriles secundario que, después de varios intentos, se mandó formar por Ley aparecida a mediados de 1904. En ella se clasificaban esta clase de ferrocarriles en dos grandes grupos: aquellos que no tenían subvención directa del Estado y los que podían obtener garantía de interés por el Estado. Dentro de estos últimos, en la primera relación de líneas que se hizo pública en abril de 1905, se incluía una que partía de la localidad valenciana de Requena, y por Casas Ibáñez y Albacete, finalizaba en la ciudad de Alcaraz, al pie de la montaña bética. En esta última localidad, igualmente, concluía otra de las líneas proyectadas, que partía de la ciudad manchega de Valdepeñas y pasaba por Infantes y Villanueva de la Fuente. De acuerdo con estas previsiones, el centro ferroviario proyectado en Alcaraz se conformaba como una estación término sin ningún sentido aparente, dada la imposibilidad de buscar una salida hacia levante por la enorme complejidad topográfica que entrañaba el recorrido. Por esa razón, la propuesta supletoria del Plan, que se hizo pública a finales de 1905, incluía una nueva línea entre la Estación de Baeza y Alcaraz, pasando 
por Úbeda y Villacarrillo, que daba continuidad hacia el sur a las dos primeras, diseñando así una red de trazado más lógico y, desde luego, mucho más atractivo para los inversores ferroviarios

Tanto para la construcción de la primera como de la última línea citada, presentó proyecto un peticionario profesional que ya había sido autorizado para otras muchas empresas ferroviarias desde finales del siglo XIX. En vista de tal circunstancia, a mediados de 1910 se abrió concurso para que en un plazo de dos meses pudieran presentarse otros proyectos en competencia con el aludido. Pero tampoco en este caso acudió ningún postor a la subasta, sin duda porque las condiciones de construcción y explotación de la línea debieron resultar muy poco atractivas. La constatación de ese fracaso, y el temor a que se abandonara definitivamente la construcción de esas líneas, impelieron al Ayuntamiento de Albacete a convocar una asamblea a la que fueron convocados todos los municipios e instituciones provinciales afectadas por el fatal resultado de las subastas. Tampoco eso sirvió de nada pues la segunda subasta, anunciada dos años después, arrojó el mismo resultado que la primera. Este nuevo fracaso lejos de hacer desistir a las instituciones y a las distintas fuerzas políticas y sociales que se habían empeñado en la creación del ferrocarril, las espoleó aun más. A partir de ese momento, a las iniciativas promovidas desde la provincia de Albacete se sumaron las fuerzas vivas del resto de las provincias a las que afectaban estas líneas (Araque Jiménez y Gallego Simón, 2007), al tiempo que se multiplicaron las acciones para conseguir su puerta en marcha inmediata. Se celebraron nuevas asambleas que fueron ganando en participación conforme pasaban los años; distintas comisiones integradas por miembros de todas las provincias afectadas visitaron a los representantes de las más altas instancias del Estado; en fin, se incrementó la presión de las fuerzas políticas y populares ante los poderes públicos en aras a conseguir la tan ansiada línea que ponía en comunicación Baeza con Utiel. Pero todo fue en vano.

Sin embargo no fue hasta advenimiento de la Dictadura de Primo de Rivera cuando se desato un verdadero estado de euforia en torno a la línea. A partir de ese momento, la persistente reivindicación de asociaciones y entidades colectivas se vio secundada por múltiples pronunciamientos a título individual de personalidades de reconocido prestigio social e intelectual en la vida de las dos provincias más interesadas en el ferrocarril. Algunos de estos individuos, tratando de darle la mayor resonancia posible al asunto, no dudaron en expresar sus opiniones a través de las páginas de la prensa nacional, mediante artículos con un matiz abiertamente reivindicativo. En ellos se exigía a los miembros del directorio militar que pusieran en marcha los mecanismos pertinentes para que la línea dejara de ser, de una vez por todas, la sempiterna promesa política en la que se había convertido durante más de dos décadas, y se transformara en una obra tangible y visible de la que pudieran sentirse orgullosos cuantos ciudadanos la venían reclamando.

No sabemos hasta qué punto surtieron efecto todas estas peticiones individuales y colectivas, pero lo cierto es que el Plan preferente de ferrocarriles de urgente construcción que se aprobó a comienzos de 1926, incluía una línea que en el texto legal se denominaba de "Baeza a empalmar con la (línea) de Cuenca-Utiel", o sea, la unión de las dos líneas de ferrocarriles secundarios que se habían propuesto en 1905, con la única modificación del la estación término de la línea, que dejaba de ser Requena para establecerse en la cercana localidad de Utiel. Aprobada oficialmente, las instituciones oficiales de Jaén y Albacete intensificaron las gestiones ante el Ministerio de Fomento para que las obras dieran comienzo en el más breve plazo de tiempo posible. En esta ocasión la delegación jiennense se mostró mucho más diligente que la albacetense, ya que sus vínculos políticos con el directorio presidido por Primo de Rivera eran más elocuentes y sus lazos más estrechos (Hernández Armenteros, 1999).

El primer escollo serio que hubo de salvar el ferrocarril Baeza-Utiel estuvo relacionado con el establecimiento definitivo de distintas porciones del trazado tanto en la provincia de Jaén como en la de Albacete. En la primera, el problema radicaba en la dirección a seguir a partir de esa estación término. Inicialmente se había previsto seguir un itinerario similar al diseñado por Francisco Coello a mediados del siglo XIX, sin embargo la fuerte presión de los grandes propietarios de la Loma de Úbeda, a la que muy pronto se sumó la Cámara Oficial de Comercio e Industria de Jaén, obligó, después de muchas tiranteces, a modificar ese recorrido en su tramo inicial. Las opiniones de aquellos terratenientes, si es que alguna vez se hicieron públicas, no las conocemos, pero creemos que están perfectamente reflejadas en los numerosos escritos de la Cámara, rubricados en ocasiones por el Presidente de la Cámara Agrícola provincial. En ellos se dejaba meridianamente claro que "seguir el trazado por la cuenca del Guadalimar es la utopía más enorme que puede alimentarse, puesto que habían de cruzarse los ríos tantas veces como kilómetros haya de recorrido, en lo que se invertiría una enorme millonada tan perfectamente inútil, como lo sería la semilla tirada a boleo en tierra infructífera" (Cámara..., 1925, 5). En cambio, siguiendo 
el valle del Guadalquivir se atravesaban pueblos "que sólo al nombrarlos dan la sensación de riqueza que poseen, riqueza que por falta de vías comunicativas no sale espontáneamente a los mercados, y cuando sale, lo hace en condiciones anormales y con un bajo precio, perjudicando de manera ostensible al productor e imposibilitando el desarrollo natural y lógico de la industria y el comercio (Cámara..., 1925, 10). Así pues, en lugar de discurrir por el valle del Guadalimar, el trazado se desvió por el valle del Guadalquivir y la cara sur de La Loma de Úbeda, con la consiguiente satisfacción de los propietarios agrícolas de La Loma y del conjunto de la población residente en todas las agrociudades que surcaba el ferrocarril, profundamente decepcionadas después de que a finales del siglo XIX se variara el recorrido de la línea Linares-Almería, alejándola definitivamente de estas tierras (Cuellar Villar, 2003). Esa modificación originó una cierta polémica que resucitaría varias veces a lo largo de la historia de la línea: se acusaba al general Saro, y por extensión a los grandes terratenientes de la zona por la que discurría el nuevo trazado, de haber variado éste a su antojo, por puro interés personal, a sabiendas de que tal modificación suponía un encarecimiento de las obras y una mayor carga para las arcas públicas. En ese momento aun no se conocían las enormes complejidades técnicas que traía aparejada esa decisión, que acabó convirtiéndose en un verdadero lastre para el desarrollo del ferrocarril.

En la provincia de Albacete aun se demoró más la decisión sobre el diseño definitivo del trazado, que también estuvo acompañado de una cierta controversia. Durante muchos años se contempló como solución más apropiada para enlazar este ferrocarril con la línea de Cuenca a Utiel, el desvío a la altura de Robledo, para buscar desde allí la dirección de La Roda y luego la de Iniesta y Minglanilla hasta desembocar en la línea de Cuenca. Semejante propuesta implicaba dejar al margen del Baeza-Utiel a la ciudad de Albacete, que tan activa se había mostrado siempre en la lucha por su consecución. Semejante propuesta no tardó en ser contestada por los detractores de este trazado, quienes advirtieron que era "una fantástica derivación propia para ser defendida por lo que saben poca geografía" (VV.AA, 1927, 14). Para demostrarlo de manera fehaciente, elaboraron un pequeño estudio sobre ambas variantes en el que se demostraba que el trazado que pasaba por la capital de la provincia era más conveniente que el desvío por La Roda puesto que resultaba menos complicado desde el punto de vista topográfico y permitía un recorrido más extenso del ferrocarril por tierras albacetenses, con lo cual se ampliaban las perspectivas de desarrollo a más localidades y, en definitiva, podía beneficiar a un mayor volumen de población. Por otro lado, el trazado resultaba mucho más aconsejable desde el punto de vista económico, tanto por la importancia que a este respecto tenía la ciudad de Albacete, como por la mayor riqueza agrícola de las zonas por las que atravesaba. Con tales argumentos, apoyados mayoritariamente por la sociedad civil albacetense, el diseño del trazado se recondujo y acabó estableciéndose por la capital de la provincia, aprovechando para ello la misma estación que se había inaugurado en 1855 para acoger el ferrocarril de Madrid a Alicante; una decisión que volviera a suscitar una nueva polémica (Santos Ganges, 2007). En efecto, esta nueva "estación de conjunto" necesitaba una ampliación sustancial que chocaba de frente con la expansión del casco urbano, por lo que muy pronto se pensó en desplazar las instalaciones ferroviarias para que éstas no interfirieran con el desarrollo urbanístico. Sin embargo la solución no era tan fácil como algunos habían previsto en un principio. De hecho se formaron distintos anteproyectos durante la Segunda República y en los primeros años de posguerra, pero la solución era tan compleja que aun transcurrirían muchos años hasta que se adoptara una solución definitiva. Y entonces esa decisión ya no estuvo condicionada en modo alguno por el ferrocarril Baeza-Utiel.

La línea tenía una longitud total de 364,9 km, de los que 249,6 km correspondían al tramo entre la Estación de Baeza y Albacete, y 115,3 km al comprendido entre esta última ciudad y Utiel. En la pro $7-$ vincia de Jaén la línea contaba con 8 estaciones y 10 apeaderos; en la de Albacete con otras 8 estaciones y 12 apeaderos, y en la de Valencia con 2 estaciones y 3 apeaderos. Como puede advertirse, el número de apeaderos era muy superior al de estaciones, lo que delata la fuerte presión que llegaron a ejercer las autoridades locales y algunos grandes propietarios agrarios para que la línea se acercara a sus municipios o a sus propiedades, a cambio de lo cual cedieron gratuitamente el suelo para el emplazamiento del viario y las edificaciones ferroviarias (Figura 1).

Además de esas edificaciones de mayor o menor envergadura, el establecimiento del viario en sus distintas fases históricas requirió de otra infraestructura mucho más potente y compleja, entre la que sobresalían los 107 túneles de distinta longitud y dificultad que hubo que excavar para salvar algunos de los principales obstáculos del trazado. Su extensión conjunta superaba los $28 \mathrm{~km}$, lo que nos da una buena idea de la dificultad y encarecimiento de las obras. Así mismo hubo que levantar un total de 25 viaductos, también de muy 
variada extensión y complejidad ${ }^{2}$. A todo lo anterior se sumaban las numerosas obras de cementación de trincheras, reforzamientos de taludes, etc., que en distintos tramos del recorrido resultaron tan complicadas y costosas como las anteriores. Téngase en cuenta que en algunas de esas partes del trazado existían graves problemas derivados de la inestabilidad de los suelos, que sólo era posible corregir mediante la construcción de enormes diques de cemento con capacidad para contener los deslizamientos y desprendimientos en masa.

Figura 1. Ferrocarril Baeza-Utiel. Tramo Baeza-Albacete

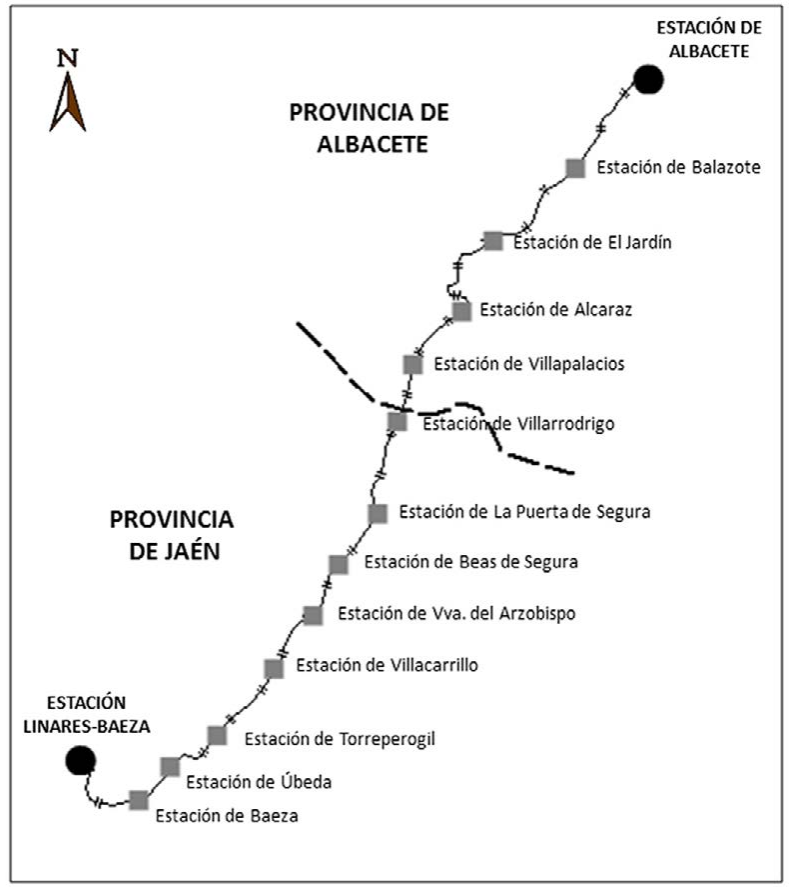

Elaboración propia

\section{INICIO DE LAS OBRAS Y PRIMERA PARALIZACIÓN}

Para la ejecución de todas esas obras de infraestructura, el trazado se dividió en cuatro grandes secciones de diferente longitud. A su vez, cada sección se subdividió en distintos trozos en razón de la mayor o menor complejidad y coste económico de cada uno de ellos. Los estudios técnicos de esas secciones se aprobaron escalonadamente entre principios de 1927 y mediados de 1928. Acto seguido se anunciaron las subastas de las obras de explanación, fábrica, edificios, túneles y accesorios correspondientes a cada sección. Tras la adjudicación, dieron comienzo las obras en los primeros trozos subastados a finales de septiembre de 1927. De inmediato, en la práctica totalidad de los municipios afectados, se incrementaron de un modo apreciable las expectativas de empleo, y en todos ellos se observó una mejora sustancial de los niveles de vida del conjunto de la población. Es más, en algunas localidades las necesidades de mano de obra crecieron de tal modo que se llegaron a generar corrientes inmigratorias hacia los mismas de una cierta relevancia demográfica. Así sucedió por ejemplo, en Beas de Segura, donde el inicio de las obras del ferrocarril vino a coincidir con los primeros trabajos de levantamiento de la presa del Tranco, lo que originó una situación de pleno empleo nunca antes conocida en esta localidad serrana (Arnal Almendros, 1983), o en Úbeda y Baeza, en los que las tasas de paro se redujeron sustancialmente y aminoraron la tremenda presión social que venían soportando estas dos agrociudades. Igual puede decirse de los pequeños municipios manchegos por los que discurría el ferrocarril, donde las obras actuaron como un auténtico revulsivo demográfico.

2 En un inventario histórico de los puentes de la provincia de Jaén realizado en 1985, se recogen las principales características técnicas de una buena parte de esos puentes (ETSICCP, 1985). A través de las fichas individuales de cada uno de ellos podemos obtener todos los detalles sobre los mismos; desde el proyectista hasta su tipología, pasando por sus características físicas y singularidades. 
Desgraciadamente, ese bienestar social duró muy poco tiempo ya que a principios de agosto de 1930 las obras del ferrocarril se paralizaron por falta de consignaciones presupuestarias. Los Ayuntamientos y las Diputaciones provinciales de Jaén y Albacete iniciaron entonces todo tipo de movilizaciones ante el Ministerio de Fomento, pero no consiguieron que sus intensas gestiones dieran ningún fruto positivo, probablemente por la fuerte inestabilidad política de aquel momento de transición. Tras la proclamación de la segunda República en abril de 1931, lejos de mejorar, las perspectivas empeoraron de forma alarmante. Una Ley promulgada a comienzos de 1932, declaró nulo el Plan preferente de ferrocarriles de 1926 por el que se había creado la línea Baeza-Utiel, lo que vino a descartar cualquier posibilidad de relanzamiento de las obras paralizadas. Un poco más tarde el Ministro de Obras Públicas Indalecio Prieto, que ya se había mostrado partidario de no gastar ni una peseta más en la apertura de nuevas líneas (Cabezas, 2005), firmó un duro decreto en el que acusaba a los redactores de aquel Plan de haberlo acordado alegremente en un viaje entre Madrid y El Escorial "sin parar mientes en las potencialidades económicas del país y sin estudiar siquiera el rendimiento económico de cada línea ni tener en cuenta indeclinables conveniencias nacionales". En consecuencia, a partir de la entrada en vigor de esa norma todas las líneas que se encontraban en ejecución y no respondían a intereses generales, sino a deseos o aspiraciones locales, quedaban al margen de la financiación estatal, que en lo sucesivo sólo se comprometía a aportar un tercio del costo de las obras que quedaran por ejecutar.

Como era de prever, la reacción de las autoridades municipales y provinciales no se dejó esperar por mucho tiempo. En una coyuntura especialmente crítica desde el punto de vista social y económico, como la que se vivió durante los primeros momentos republicanos, la oportunidad que representaba el ferrocarril ya no residía tanto en su capacidad para romper el aislamiento, sino en su eficacia a la hora de generar empleo alternativo al que proporcionaba el sector agrario, que tampoco pasaba entonces por sus mejores momentos. Por esa razón, dirigentes socialistas de las provincias de Jaén y Albacete, aunque no desautorizaron públicamente a Prieto, e incluso se negaron a participar en algunos de los actos de desagravio programados a raíz de esta decisión, tampoco dejaron de maniobrar en la sombra para tratar de contrarrestar los efectos laborales de esta medida, que dejaba al partido y a las instituciones en las que gobernaba en una situación muy debilitada frente a la clase trabajadora, cada vez más radicalizada por la carencia de perspectivas de empleo.

Las muestras de la inquietud popular afloraron en la multitudinaria asamblea celebrada a principios de junio de 1933 en Albacete, a la que acudieron, además de centenares de personas a título individual, los principales representantes institucionales de esa provincia y de las de Jaén, Ciudad Real, Cuenca y Valencia. En ese acto multitudinario volvió a exigirse al gobierno que pusiera fin a esa paralización del ferrocarril que situación que tanto perjuicio económico y malestar social estaba acarreando. Para comunicar esa demanda, una comisión surgida de la asamblea se trasladó a Madrid a fin de conversar y entregar directamente al Ministro de Obras Públicas el escrito donde se recogían todas sus reivindicaciones. Éstas y otras acciones del mismo tenor, contribuyeron a la creación de un clima social muy similar al que había precedido al establecimiento del ferrocarril. Por la simple fuerza de la lógica, el encauzamiento de esas aspiraciones no podía desembocar más que en una decisión política que pusiera fin a la paralización de la obras y autorizara su reanudación con bríos renovados. Ese nuevo horizonte quedó completamente despejado tras el primer gran cambio de gobierno que sucedió a las elecciones republicanas de finales de 1933. Un Decreto de febrero del año siguiente firmado por el nuevo Ministro de Obras Públicas, Rafael Guerra del Río, venía a reactivar las obras de todas aquellas líneas férreas en las que ya se llevaban invertidas una gran cantidad de caudales públicos, que un país como España no podía permitirse el lujo de despilfarrar, máxime si dichas líneas venían a completar el sistema radial de ferrocarriles, como era el caso de la línea Baeza-Utiel. De acuerdo con ello, el texto legal establecía que todas las líneas comprendidas en el Plan preferente de 1926, más aquellas otras acordadas por el Parlamento e iniciadas con anterioridad a esa fecha, cuyas obras se encontraran en curso de ejecución, proseguirían por cuenta exclusiva del Estado. Por el contrario, éste no construiría ninguna otra línea cuya ejecución no hubiera comenzado, aun cuando estuviera incluida en planes anteriores. De cara a la finalización de las obras, las líneas afectadas se clasificaban por "orden de urgencia para su terminación", de acuerdo con lo que se hubiera invertido en cada una de ellas hasta ese momento (31 de diciembre de 1933), así como de lo que quedara por invertir. Aunque los datos que figuraban en los anexos que acompañaban al Decreto estaban equivocados, no cabe ninguna duda de que el ranking estaba encabezado por el ferrocarril Baeza-Utiel, en cuya ejecución se llevaban gastados, en la fecha citada, un total de 110,6 millones de pesetas del total de 227,6 millones 
de pesetas presupuestados inicialmente. Parecía lógico, en consecuencia, que una obra pública en la que ya se había invertido casi el $65 \%$ de su coste total, no se abandonara y se malgastaran así unos fondos públicos que tanto esfuerzo había costado conseguir.

Consecuentemente, a partir de la promulgación de ese decreto, en fecha que no podemos precisar con exactitud, las obras se retomaron en el mismo punto en el que se habían abandonado cuatro años antes. Pero la reactivación fue sumamente efímera ya que tras el inicio del levantamiento militar de julio de 1936, y el posterior desencadenamiento de la guerra civil, las obras sufrieron una brusca ralentización, si bien no llegaron a paralizarse por completo. El hecho de que la zona por la que discurría la línea hubiera permanecido leal al gobierno legítimo de la Republica, permitió seguir aplicando al trazado ferroviario distintas partidas presupuestarias hasta mediados de 1937, año en el que se aprobaron pagos por un valor cercano a los 6,5 millones de pesetas en las cuatro secciones del ferrocarril. Desde entonces, la acuciante asfixia financiera del gobierno republicano sólo permitió inversiones muy diminutas, incapaces por sí solas para sufragar las mínimas labores de conservación de las explanaciones y obras de fábrica que se habían ejecutado hasta ese momento. Esa falta de consignaciones ocasionó enormes perjuicios derivados del deterioro que experimentaron algunos trozos del trazado, que obligó a rehacerlos casi por completo una vez concluido aquel episodio bélico tan absurdo como sangriento.

\section{REACTIVACIÓN DE LAS OBRAS. INCLUSIÓN EN EL PLAN JAÉN}

La difícil situación económica en la que se vio inmersa España tras la guerra civil, no era la más apropiada, obviamente, para abordar el conjunto de obras que restaban para la finalización del trazado. A pesar de ello, el nuevo régimen político no tardó en dar muestras de su decidido empeño por concluir las obras de la línea Baeza-Utiel. Ahora más que nunca se necesitaba una línea alternativa para movilizar al ejército, en caso de que quedara interrumpida la línea tradicional que ponía en conexión la capital de España con el sur peninsular.

Prueba concluyente de lo que decimos la encontramos a mediados de 1942, momento en que, a pesar de las severas restricciones económicas, se consignó una inversión de más de 10 millones de pesetas con destino a las obras de la nueva variante proyectada en el origen del trazado, allí donde la línea enlazaba con el nudo ferroviario de la Estación de Baeza, que en ese momento ya se encontraba totalmente en manos de la recién creada Red Nacional de los Ferrocarriles Españoles (RENFE). Para conseguir ese acceso hubo que salvar el río Guadalimar a $4 \mathrm{~km}$ del inicio de la línea, cerca de la central eléctrica del Arquillo, mediante la construcción de un espectacular puente en curva de $210 \mathrm{~m}$ de longitud y $20 \mathrm{~m}$ de altura sobre rasante. Compuesto de "cinco bóvedas parabólicas de hormigón, de 30,4 m de luz cada una y dos bóvedas laterales de medio punto de $10 \mathrm{~m}$ de luz" (ETSICCP, 1985), posiblemente sea la obra más emblemática de toda la línea tanto por su extensión como por su bella factura. En el momento en que se redactó el proyecto de la línea no se había previsto ese enlace, cuya solución técnica se había ido dilatando año tras año hasta que no quedó más remedio que abordarlo para cerrar por completo el trazado.

Tres años después se aprobó otra inversión que triplicaba la anterior, destinada en este caso a obras en tres trozos de la sección primera de la línea, la que discurría por los inestables terrenos de la Loma. En el momento en que se aprobó la modificación del trazado en esta parte inicial del mismo, los técnicos habían advertido de algunos de los inconvenientes que planteaba esta decisión, dados los frecuentes deslizamientos de tierras que tenían lugar sobre unas laderas con abundante presencia de margas arcillosas. A pesar de que las pendientes no eran excesivamente elevadas, los potentes bancos margosos daban origen a frecuentes fenómenos de reptación de una enorme capacidad destructiva. Eso obligó al establecimiento de numerosos túneles forzados allí donde mayores facilidades se daban para los movimientos masivos de tierras, lo que acabó elevando sustancialmente el coste de las obras en esta parte de la línea.

Pero cuando la línea sufrió una verdadera reactivación fue tras la entrada en vigor del Plan de obras, colonización, industrialización y electrificación de la provincia de Jaén, aprobado por el gobierno en julio de 1953. La comisión que redactó el estudio en el que se fundamentó el conocido popularmente como Plan Jaén, consideraba esta línea férrea como una pieza esencial para la potenciación del desarrollo económico y social del amplio ámbito geográfico por el que discurría, profundamente deprimido y atrasado a pesar de contar con recursos naturales y agrarios de suficiente entidad y muy variados. De acuerdo con los datos que manejaban sus redactores, referidos exclusivamente a Jaén, el ferrocarril atravesaba una zona de olivar que se extendía sobre más de 100.000 ha y daba una producción media de 34.000 Tm anuales 
(Puig, 1960). Entrelazadas con las plantaciones olivareras -aun no se había manifestado el monocultivo en toda su plenitud- los campos de cultivo cerealistas ocupaban 118.000 ha y arrojaban una producción media anual de 25 millones de kilogramos. Además, la línea bordeaba las Sierras de Segura y Cazorla, de las que anualmente se extraían $50.000 \mathrm{Tm}$ de madera. Toda esta gran despensa agraria se hallaba a una distancia media del ferrocarril que superaba los $50 \mathrm{~km}$, pero se reduciría a tan solo 15,9 kilómetros a partir del establecimiento de la línea.

Contemplado desde esa perspectiva, quedaban muy pocas dudas acerca de la excepcional oportunidad que representaba la conclusión del trazado. Por esta razón, la Ley mediante la cual se aprobaba el Plan consignaba una partida de casi 1.100 millones de pesetas para atender las necesidades ferroviarias de la provincia. De dicha cantidad 657 millones correspondían a la línea Baeza-Utiel y los restantes 437 millones al tramo Argamasilla de Alba-Marmolejo de la línea Córdoba-Puertollano, considerada de interés estratégico por constituir una alternativa al desplazamiento militar entre el centro de España y Andalucía en caso de interrupción del paso de Despeñaperros. Semejante montante global era el segundo en importancia, después del dedicado a construcción de pantanos, de cuantas partidas contemplaba el Plan Jaén, pues representaba nada menos que el $27,7 \%$ del total de inversiones previstas en el mismo, cifrado en cerca de 4.000 millones de pesetas (Ortega Campos, 1973). Ahora bien, dicha cantidad total se distribuiría en 15 anualidades, cuyo importe anual no podía superar en ningún caso el $10 \%$ de la cuantía total. La única condición que establecía el texto de la Ley era que la ejecución de los trabajos a los que afectaba esta partida no podrían comenzar mientras no se redujeran en no menos de 50 millones las inversiones que coetáneamente estaban teniendo lugar en las obras del ferrocarril Zamora-La Coruña, cuya prioridad era máxima. Sólo reparó en esta crucial decisión un informe emitido años después por las Cámaras de comercio de Jaén y Albacete, al que luego nos referiremos, que achacaba a este imperativo legal la imposibilidad de finalización de la línea en el primer periodo de vigencia del Plan Jaén. De no haber sido por esa eventualidad, se aseguraba, el ferrocarril se hubiera terminado mucho antes.

Figura 2 Evolución de las Inversiones efectuadas en el ferrocarril Baeza-Utiel (1927-1964).

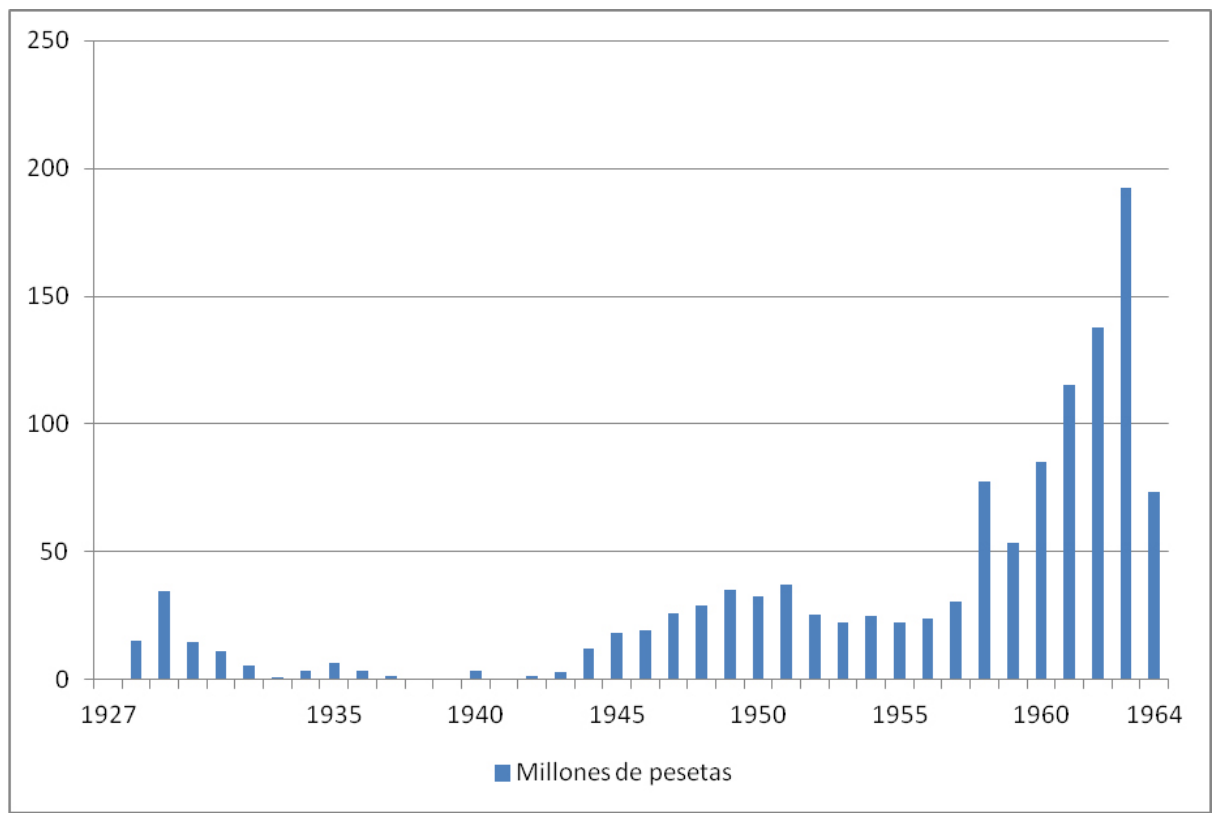

Aún con esta rémora, como podemos apreciar en la Figura 2, las inversiones comenzaron a crecer paulatinamente desde mediados de los años cincuenta, y alcanzaron su cenit a finales de esa década y principio de la siguiente, al coincidir las partidas económicas procedentes del Plan Jaén con las que se programaron en la provincia de Albacete en 1959, cuyo monto ascendía a 239 millones de pesetas (Cebrián Abellán, 2011). Durante estos años se llevaron a cabo todas las obras de reforma que había sufrido el proyecto original, obsoleto en muchos aspectos después de los años que habían transcurrido desde que se proyectó. Se construyeron los viaductos y túneles más caros y de mayor envergadura y complejidad técni- 
ca, los cuales no habían podido abordarse con anterioridad por falta de medios económicos; se edificaron las estaciones ferroviarias y sus dependencias anexas, a veces de mayor volumen edificatorio que los propios edificios de viajeros; se ejecutaron todas las obras de fábrica anexas al trazado; se solventaron todos los problemas jurídicos que habían quedado pendientes tras los procesos de expropiación; en definitiva, se dejó expedita la línea para su funcionamiento, especialmente en el tramo que partía de la estación de Albacete, donde a lo largo de más de 100 kilómetros quedó tendido el balasto e implantados los raíles, a falta sólo de colocar las señales y tender las líneas de telecomunicaciones y abastecimiento eléctrico a las distintas dependencias ferroviarias. En el tramo jiennense, las obras estaban algo más retrasadas, especialmente en la primera sección, pero en algunos trozos ya se había acopiado todo el balasto necesario para la implantación de las vías, que se creía inminente. De hecho a mediados de diciembre de 1962 se anunció la celebración del concurso para la ejecución de las obras de instalación de las vías en las dos primeras secciones, pero unos días después se suspendió. La resolución de la Dirección general de ferrocarriles, sumamente lacónica, afirmaba que "la conveniencia de tener en cuenta los resultados de determinados estudios en curso de realización en materia de ferrocarriles" aconsejaba esa decisión.

\section{SUCESIÓN DE INFORMES CONTRAPUESTOS}

Paradójicamente, cuando las inversiones en la línea Baeza-Utiel alcanzaban su punto más álgido, un estudio encargado por RENFE en 1961, relativo a la viabilidad económica de las líneas férreas que en aquellos momentos estaban en funcionamiento, así como de las que se encontraban en construcción, cayó como un jarro de agua fría entre los defensores a ultranza de este medio de transporte. En dicho estudio se apostaba por la paralización inmediata de todas las obras que estaban ejecutándose en las nuevas líneas en esos momentos, entre ellas la que nos ocupa. No obstante, se recomendaba no abandonar ninguno de esos trazados y mantenerlos bien conservados con el menor gasto posible, a la espera de que cambiaran las circunstancias económicas y volvieran a darse los supuestos que se habían manejado en 1926 para la creación de esos ferrocarriles. En el caso de la línea Baeza-Utiel el informe estimaba unas pérdidas anuales que cifraba en 16,28 millones de pesetas; un déficit muy elevado si tenemos en cuenta que para toda la red ferroviaria integrada en RENFE las pérdidas ascendían a 47,57 millones de pesetas.

El panorama sombrío que dibujo el informe encargado por RENFE, lo refrendó un año después, en 1962, el Banco Mundial en un estudio sobre la economía nacional que le había solicitado el gobierno con el fin de que este alto organismo financiero le recomendara aquellas medidas más pertinentes que debían incluirse en el primer Plan de desarrollo español (1964-1967). En línea con el informe de RENFE, el organismo internacional aconsejaba al gobierno español la concentración de las inversiones ferroviarias en las líneas que se encontraban en funcionamiento, para las cuales podían solicitársele los correspondientes créditos. Así mismo sugería la paralización de las obras de aquellos ferrocarriles que aun no se habían terminado, y proponía la realización de un estudio específico sobre los mismos, que determinara con precisión la conveniencia o inconveniencia de proseguir su ejecución (Banco Internacional de Reconstrucción y Fomento, 1962; Comín et al., 1998). De nada sirvió el hecho de que tanto el Plan de ferrocarriles de 1926, como el Plan Jaén, estuvieran en vigor, pues ninguno de los dos se había derogado expresamente, ni tampoco la constatación de lo avanzadas que se encontraban las obras del ferrocarril Baeza-Utiel; nada de eso se tuvo en cuenta en la recomendación, de modo que los trabajos volvieron a paralizarse por completo a partir de 1964.

Como había recomendado el Banco Mundial, el Ministerio de Obras públicas encargo en 1963 un informe sobre la viabilidad de las tres líneas que se hallaban más avanzadas en su construcción, esto es, la de Madrid-Burgos, la de Ferrol-Gijón y la de Baeza-Utiel. En relación con esta última, el informe emitido por el Consejo Superior de Transportes era concluyente en el sentido de que había que proceder a la terminación de la línea. Se basaba para ello en distintos argumentos que ya se habían barajado con anterioridad y en otros que habían elaborado expresamente para la redacción de este informe. Entre estos últimos sus autores destacaban que el ingreso por kilómetro de esta línea -831.000 pesetas- era superior al ingreso medio de RENFE, y que sólo quedaba por invertir el $21 \%$ del coste total de las obras. Así mismo resaltaban la importancia de los yacimientos mineros en la zona por la que atravesaba el ferrocarril dentro de la provincia de Jaén, que consideraban la de mayor importancia en cuanto a reservas de mineral de plomo de toda España, con más de 300 concesiones de explotación aprobadas. Si la mayoría de estos yacimientos aun no habían podido empezar a explotarse, era, precisamente, por falta de medios de transporte capaces de trasladar los productos obtenidos hasta el mercado o hasta las plantas de transformación. 
Lo mismo sucedía con los abundantes yacimientos de hierro, todos ellos denunciados y aprobados, pendientes únicamente de que dieran comienzo los trabajos de explotación. En este caso se había llegado, incluso, a solicitar por parte de una empresa minera la oferta de precios a RENFE para trasladar desde la estación de Arroyo del Ojanco hasta el norte de España una cantidad de mineral de hierro que oscilaba entre las 30.000 y $35.000 \mathrm{Tm}$ anuales. Esas magníficas perspectivas económicas eran las que empujaban al Consejo Superior de Transportes a pedir la prosecución de las obras de la línea, que en explotación arrojaría un balance mucho más rentable que el de la propia RENFE. Junto a ello, la confirmación de que sólo quedaba una quinta parte de la inversión por realizar para completar la línea, llevaba a sus redactores a la conclusión de que la obra era merecedora de ser incluida en el primer Plan de Desarrollo español.

Todo lo contrario se desprendía de otro informe sobre las condiciones técnicas y económicas de explotación de las tres líneas aludidas, encargado ese mismo año por la Comisaría del Plan de desarrollo a la empresa consultora francesa Sofrerail (Comisaría del Plan de desarrollo, 1963). A ésta se le pedía que estableciera un orden de prioridad económica, definiera el programa de realizaciones y recomendara, en su caso, las líneas ferroviarias que debían ser abandonadas.

De acuerdo con los datos elaborados por esta consultora, relativos a la línea Baeza-Utiel, desde un punto de vista estrictamente económico no era recomendable la continuación de los trabajos. Ahora bien, el volumen de pérdidas económicas calculado no era tan abultado como para abandonar definitivamente la línea, por lo que se sugería suspender la ejecución del trazado durante un plazo de cinco años, y volver a realizar un estudio al cabo de ese tiempo por si las circunstancias hubieran cambiado y resultara justificada la continuación de los trabajos.

A la vista del informe de Sofrerail, que acabó siendo determinante, el Ministerio de Obras Públicas acordó interrumpir las obras temporalmente. Esa decisión se incorporó de inmediato al primer Plan de desarrollo, que únicamente autorizó aquellos gastos de la línea que ya estaban comprometidos en los contratos de ejecución efectuados con anterioridad. Aunque casi nadie fuera consciente de ello, en ese momento se estaba dando por caducada una línea férrea que durante muchos años había mantenido en vilo a las instituciones y a la sociedad de unas provincias olvidadas, a las que una vez más se condenaba al ostracismo ferroviario.

A diferencia de las paralizaciones de antaño, en esta ocasión no afloraron con tanta fuerza las voces que disentían de esta decisión gubernamental. Bajo el asfixiante clima político que vivía España en aquel momento, con todas las libertades personales suprimidas o coartadas, únicamente se atrevieron a alzar la voz, y eso de forma muy cauta y comedida, algunos de los representantes de la organización sindical, a pesar de que todos ellos, en mayor o menor medida, se hallaban muy comprometidos en la defensa del régimen de Franco. En distintos consejos sindicales de ámbito comarcal, provincial o regional se dejaron oír esas voces críticas que cuestionaban la nueva paralización del Baeza-Utiel. Así sucedió, por ejemplo, en el Consejo sindical interprovincial del sudeste de España, en el que se integraban representantes pertenecientes a las provincias de Murcia, Alicante, Almería y Albacete, que en una reunión en la capital manchega a mediados de enero de 1967, acordaban solicitar la reanudación de las obras del ferrocarril con carácter de urgente. Se basaban en el interés nacional que tenía la línea así como en las elevadas inversiones que se habían realizado en la misma, cifradas en el 81 \% de su coste total. Es más, como quiera que el tramo comprendido entre Bienservida y Albacete se encontraba pendiente de una mínima inversión para su total terminación, se pedía al gobierno que acelerara esas obras para que la línea pudiera entrar en servicio en ese trayecto mientras que se completaba el resto de la infraestructura ferroviaria.

Mucho más timoratos se mostraron en todo momento los representantes sindicales jiennenses, incapaces no ya de revelarse contra esta decisión, sino de ponerla mínimamente en cuestión. Ni siquiera cuando el objeto de sus deliberaciones era una comarca como la de La Loma, a la que tanto afectaba el ferrocarril, fueron capaces de pronunciarse sin tapujos sobre la paralización de las obras. En un estudio elaborado en 1966 por el Consejo económico sindical provincial de Jaén sobre esa comarca, sus redactores se limitaban a mostrar la preocupación que suscitaba en la zona el reciente cierre de la línea de tranvía entre Úbeda y la Estación de Baeza, con ramificaciones a Linares y Baeza, pero únicamente mencionaban la línea Baeza-Utiel para confirmar que seguía sin terminarse, sin más comentarios ni observaciones sobre el futuro de la misma (CESP, 1966).

El tiempo transcurrido desde que se llevaron a cabo los primeros informes sobre la viabilidad de la línea, unido a las pocas voces disonantes que de cuando en cuando surgían en el seno de la organización sindical franquista, indujeron al Ministerio de Obras Públicas, a comienzos de 1967, a crear una comisión 
de trabajo que actualizara los estudios que se habían venido realizando desde comienzos de esa década. Tal y como se afirmaba en el preámbulo de la norma mediante la cual se creaba dicha comisión, los cambios que había experimentado la economía española en el transcurso de los primeros años sesenta, aconsejaban efectuar dicha actualización por si se considerase oportuno revisar las decisiones que se habían tomado en su momento respecto a la paralización del ferrocarril, o, en todo caso, para establecer la estrategia a seguir en el futuro respecto al aprovechamiento de las obras ya realizadas.

Integrada por personal técnico del Ministerio de Obras Públicas y por otros miembros de RENFE, la comisión pidió informe a las cámaras de comercio de Jaén y Albacete, a sabiendas, sin duda, de que habían sido las dos instituciones que más habían luchado por la constitución de la línea, y que más activas se habían mostrado en su defensa. Los dos entes camerales, de manera conjunta, encargaron a la consultora Pleco la elaboración de un estudio sobre la viabilidad de la línea férrea, que se publicó por la primera de ellas antes de finales de ese mismo año (Cámara Oficial de Comercio e Industria, s. f.) ${ }^{3}$. El amplio y documentado informe elaborado por la empresa contratada, loado por cuantos lo leyeron, no se limitaba a exponer los criterios y mostrar los datos que sustentaban su decisión final, sino que criticaba, a veces con extrema dureza, las hipótesis y conclusiones a las que habían llegado otros informes anteriores situados en sus antípodas.

Especialmente duras y extensas eran las críticas al informe elaborado por Sofrerail, que consideraban en el origen de la errónea paralización de la línea. Según se aseguraba, la consultora francesa había utilizado una metodología inadecuada que tendía a infravalorar los beneficios y aumentar los costes de la línea, además de cometer errores de bulto en los cálculos y fundamentación de sus hipótesis de partida. En efecto, si se corregían los cálculos de Sofrerail, utilizando datos mucho más verosímiles, podía probarse que los balances empresariales arrojaban unos resultados muy positivos para la línea Baeza-Utiel, que no solo no era deficitaria, sino que, a la vista de las previsiones, en 1973 acabaría dando unos beneficios superiores a los 39 millones de pesetas. De ahí que las dos cámaras, al tiempo que rechazaban el cierre de la línea, pidieran un adelanto de tres o cuatro años en su entrada en explotación.

Por si la demostración de esos errores no bastara, la consultora Pleco argüía en defensa de la continuación de las obras de la línea, que éstas se hallaban ejecutadas en casi sus cuatro quintas partes (78\% del total), esto es, se había terminado toda la explanación del trazado así como las obras de fábrica y los túneles en el trayecto comprendido entre Jaén y Albacete; estaban colocadas las vías férreas en $80 \mathrm{~km}$ del recorrido a partir de esta última ciudad; y se habían terminado casi todos los edificios de viajeros y otras dependencias de las estaciones ferroviarias. En suma, como afirmaban los redactores, la línea se encontraba a falta de la colocación de las "últimas piedras".

Por lo demás, el informe encargado por las cámaras contenía un documentado y minucioso estudio sobre el hinterland del ferrocarril ${ }^{4}$, que en muchos aspectos venía a reforzar esa posición favorable a la puesta en servicio de la línea. Como ponían de relieve los datos del Censo de población de 1950 y del Padrón municipal de 1965, en todo ese hinterland se había iniciado un proceso de despoblación que aun podía considerarse incipiente, algo más intenso en la porción correspondiente a la provincia de Albacete y casi inapreciable aún en la de Ciudad Real. El conjunto de la zona había perdido 56.000 habitantes entre esas dos fechas (casi una cuarta parte de la población empadronada en 1965), a pesar de lo cual aun mantenía una estructura poblacional de cierto atractivo para el ferrocarril, derivada, sobre todo, del tamaño demográfico de sus núcleos, la mayoría de ellos comprendidos entre 1.000 y 10.000 habitantes. No podía decirse lo mismo cuando se analizaban los datos de densidad de población. En ese aspecto, como reconocían explícitamente los autores del trabajo, "la situación de la zona es francamente desfavorable respecto a la media española, puesto que su densidad por $\mathrm{km}^{2}$ viene a representar solamente el $41 \%$ de la nacional" (Cámara Oficial de Comercio e Industria, s.f., 35).

En cuanto a la producción agrícola, íntimamente asociada a la dedicación del suelo, la situación era sumamente heterogénea. Con los datos sobre cultivos actualizados, el olivar ya descollaba sobre el cereal en la provincia de Jaén (116.022 ha del primero frente a 70.000 ha del segundo), mientras que en Albacete se registraba una situación de auténtico monocultivo cerealista (143.771 ha), y en Ciudad Real

3 Aunque el texto de este informe no está fechado, algo muy habitual en esta clase de publicaciones, su publicación se realizó durante 1967, pues el último día de ese año se había establecido como fecha tope para entregar los trabajos de la Comisión.

4 En esa zona de influencia se comprendían un total de 64 términos municipales pertenecientes a las provincias de Jaén (32 municipios), Albacete (24 municipios) y Ciudad Real (8 municipios), todos los cuales ocupaban una extensión de algo más de 9.000 km². 
alcanzaba una cierta notoriedad la vid, aunque los cereales seguían predominando ( 26.650 ha de uno por 6.600 ha del otro). El principal hándicap radicaba en los escasos rendimientos por hectárea de todos esos cultivos, dado el predominio de las tierras de secano. A pesar de todo, el ferrocarril podía contribuir a la ampliación de los mercados de esos productos y a una más rápida y fácil comercialización de los mismos.

\section{INFORME FINAL DEL MINISTERIO DE OBRAS PÚBLICAS Y PARALIZACIÓN DEFINITIVA DE LAS OBRAS}

La Comisión creada en el seno del Ministerio de Obras Públicas, tras estudiar concienzudamente el contenido de todos los informes anteriores, fue la última en manifestar su opinión, que hizo pública en un largo trabajo que vio la luz en 1968 (Ministerio de Obras Públicas, 1968). En el mismo se sintetizaban perfectamente los métodos de cálculo seguidos y los resultados alcanzados en cada uno de los trabajos elaborados hasta ese momento, al tiempo que se aportaban nuevos datos elaborados ex profeso por la propia Comisión, todos ellos de una enorme trascendencia para el porvenir inmediato de la línea; datos que estaban relacionados con el tráfico ferroviario y con la proyección futura de la demanda, así como con la estructura socioeconómica de la zona por la que atravesaba el ferrocarril. En conjunto, resultaban mucho más completos que los que se habían barajado a la hora de formular el Plan Jaén, puesto que ahora se incluían también los referentes a las provincias de Albacete y Ciudad Real que antes no se habían tenido en cuenta.

No podemos hacer aquí un resumen de todas las aportaciones efectuadas en ese trabajo, pero si queremos referirnos a las consideraciones más sobresalientes de tan documentado informe. A este respecto una de las cuestiones que consideramos más interesantes es el análisis que se hacía sobre la situación real en la que se encontraba la línea en aquellos momentos, mucho más pormenorizado que el que habían hecho los trabajos anteriores. De las tres secciones comprendidas entre Jaén y Albacete, la menos adelantada era la primera debido a la ya citada inestabilidad del terreno, que obligaba a sustituir terraplenes por viaductos en distintos trozos de la misma. En cambio en la sección tercera estaba terminada la infraestructura y la vía, y en la segunda sólo quedaban por ejecutar algunas obras complementarias de infraestructura. En todas esas obras, aplicando los índices correctores de actualización de precios, se habían invertido hasta finales 1967 un total de 3.538 millones de pesetas. Quedaban por invertir otros 1.245,26 millones de pesetas $^{5}$, desglosados por capítulos de la forma que presentamos en la Tabla 1.

Tabla 1. Inversiones pendientes de realizar en 1968

\begin{tabular}{|l|c|c|}
\hline \multicolumn{1}{|c|}{ Capítulo } & Inversión (pts.) & $\%$ \\
\hline Infraestructura & 189,15 & 15,2 \\
\hline Vía y aparatos & 594,13 & 47,7 \\
\hline Señalización & 226,33 & 18,2 \\
\hline Suministro de energía eléctrica & 76,53 & 6,1 \\
\hline Telecomunicaciones & 36,83 & 2,9 \\
\hline Imprevistos & 122,29 & 9,8 \\
\hline Total & 1245,26 & 100 \\
\hline
\end{tabular}

Fuente: Ministerio de Obras Públicas (1968). Elaboración propia.

Este enorme esfuerzo inversor la Comisión lo valoraba muy positivamente, del mismo modo que el aceptable nivel tecnológico de la línea en relación con el volumen de tráfico previsible. Por otro lado, se reconocían importantes ventajas desde el punto de vista económico y social al trazado, que acortaba la distancia y el tiempo de desplazamiento entre Baeza y Albacete, y reducía los costes de transporte de viajeros y mercancías, todo lo cual podía contribuir positivamente al desenclavamiento de esta amplia región del interior peninsular a caballo entre Andalucía y La Mancha. A pesar de ello, una vez calculados los ingresos y los gastos de la línea a partir de los tráficos de viajeros y mercancías esperados, se llegaba a la dolorosa conclusión de la falta de rentabilidad de la misma, por lo que la Comisión ministerial entendía que no era aconsejable, por el momento, la continuación de las obras. Se recomendaba, eso sí, que transcurridos dos años, o sea, en 1970, volvieran a actualizarse los tráficos proyectados por si se hubiera producido alguna desviación respecto a lo observado en 1968, que viniera a mejorar sensiblemente los

5 En el texto figuraban 1.235,26 millones de pesetas debido a un error en la suma de las diferentes partidas. 
resultados económicos y situara a la línea en el umbral de la rentabilidad. Entre tanto, se aconsejaba la conservación cuidadosa de las obras e instalaciones que se habían ejecutado hasta aquel momento.

A pesar de que el estudio que la Comisión había previsto que se realizara en 1970 nunca llegó a efectuarse, y que no se dio ningún paso de cara a la activación de las obras de la línea, la idea de poner en marcha el ferrocarril nunca desapareció, si bien es verdad que las voces que lo reclamaban dejaron de oírse con tanta fuerza e insistencia como antaño. Únicamente seguían acordándose del ferrocarril algunos miembros de la agonizante Organización sindical en sus ya aludidos consejos, pero sus quejas rara vez llegaban a traspasar la esfera de esas reuniones. Tras el advenimiento de la democracia y la desaparición del sindicalismo vertical, hubo un momento en que el ferrocarril pareció dejar de interesar a las instituciones públicas y a los partidos políticos que acababan de legalizarse en España, y prácticamente no volvió a hablarse del mismo hasta que a finales de 1976, con motivo de la elaboración del Plan director territorial de coordinación de Andalucía, de nuevo se encargó a una empresa consultora la realización de un estudio sobre la viabilidad de la línea (EYSER, 1978).

En esta ocasión se incluían dos novedades muy importantes en la petición. En primer lugar se requería a la empresa contratada el estudio de variantes alternativas al trazado de la primera sección del ferrocarril, a fin de sortear los inestables suelos de la comarca jiennense de La Loma, que tantos quebraderos de cabeza habían planteado al cuerpo técnico. Se pretendía con ello evitar una zona que no había dejado de dar problemas y encarecer las obras desde que comenzó a ejecutarse el ferrocarril. De todas las opciones manejadas por los redactores, se seleccionó finalmente la denominada variante del Condado, que partía de la estación de Vadollano, situada 7 kilómetros al norte de la estación de Linares-Baeza, y remontando el valle del Guadalimar recorría la comarca jiennense que daba nombre a la variante, e iba a empalmar con la línea ya construida en la estación de Arroyo del Ojanco, es decir, un trazado similar al ya citado de Coello, que se había mantenido en distintos proyectos posteriores de enlace ferroviario entre Andalucía y Levante. En segundo lugar, el estudio debía contemplar la posibilidad de electrificación de la línea para hacerla menos dependiente de los precios del petróleo, cuyo encarecimiento había dado origen a la fuerte crisis económica por la que en esos momentos atravesaba España.

Teniendo en cuenta estos planteamientos, la consultora EYSER llegaba a la conclusión de que tanto el trazado ya construido como el alternativo, precisaban de inversiones muy elevadas para su entrada en funcionamiento, cifradas en casi 2.900 millones en el primer caso, y en más de 3.600 millones en el segundo (Tabla 2). En el primero, lógicamente, la partida más abultada correspondía a los gastos de electrificación, mientras que en el segundo los gastos de mayor importancia eran los relativos a la infraestructura necesaria para la implantación del viario (expropiaciones, explanaciones, etc.). Aun con todo, consideraban más apropiado el trazado alternativo por su mayor rentabilidad respecto al tradicional, aunque en ambos casos la cuenta de resultados resultaba negativa. Las ventajas de la variante del Condado residían en la mayor calidad técnica del trazado, su proximidad a los numerosos yacimientos de mineros enclavados en la porción nororiental de la provincia de Jaén y el ahorro en gastos energéticos del ferrocarril. En cualquier caso ninguna de las dos opciones barajadas podía contribuir a solventar los graves problemas que padecía esta región. Al respecto, el estudio era concluyente: "no cabe esperar ni que el ferrocarril potencie en gran medida el desarrollo de la zona, ni que el tráfico generado por éste justifique la puesta en servicio del ferrocarril".

Tabla 2. Inversiones pendientes de realizar en 1978

\begin{tabular}{|l|r|r|r|r|}
\hline \multicolumn{1}{|c|}{ Capítulo } & \multicolumn{2}{c|}{ Trazado actual } & \multicolumn{2}{c|}{ Trazado alternativo } \\
\hline & $\begin{array}{c}\text { Inversión } \\
\text { (pts.) }\end{array}$ & \multicolumn{1}{c|}{$\%$} & \multicolumn{1}{c|}{$\begin{array}{c}\text { Inversión } \\
\text { (pts.) }\end{array}$} & \multicolumn{1}{c|}{$\%$} \\
\hline Proyectos & 110,4 & 3,8 & 138,8 & 3,8 \\
\hline Infraestructura & 332,9 & 11,5 & $1.584,2$ & 43,6 \\
\hline Superestructura & 957,9 & 33,1 & 661,5 & 18,2 \\
\hline Estaciones & 27,0 & 0,9 & 63,0 & 1,7 \\
\hline Electrificación & $1.084,0$ & 37,5 & 876,0 & 24,1 \\
\hline Señalización y comunicaciones & 376,5 & 13,0 & 304,5 & 8,4 \\
\hline Total & $2.888,7$ & 100 & $3.628,0$ & 100 \\
\hline
\end{tabular}

Fuente: EYSER (1978). Elaboración propia. 


\section{LA LINEA EN EL CONGRESO DE LOS DIPUTADOS Y EN EL SENADO}

Al tiempo que se daban a conocer los resultados del estudio de la consultora EYSER, la línea comenzó a ser objeto de atención en el Congreso de los Diputados y en el Senado. El ferrocarril Baeza-Utiel se convirtió en una de las armas arrojadizas con las que el grupo parlamentario del PSOE fustigó a los debilitados gobiernos de la UCD. En distintas ocasiones y por distintos procedimientos los miembros de este grupo político interpelaron al gobierno acerca de sus intenciones sobre este trazado. En una labor de zapa muy bien estudiada, los congresistas y senadores socialistas acorralaron a unos ministros dispuestos permanentemente a nadar entre dos aguas, ninguno de los cuales osó manifestarse abiertamente sobre el futuro inmediato del ferrocarril. Esquivando como podían las acometidas socialistas, jamás se pronunciaron con contundencia sobre alguna de las dos alternativas posibles que estaban sobre el tapete: reapertura o cierre de la línea. Era la mejor estrategia para tratar de mantener la enorme bolsa de votos que en las elecciones generales de 1977 había aupado al gobierno a la UCD.

El primero en responder a este acoso político fue el Ministro de Transportes y Comunicaciones en 1978. En un primer momento en el Senado, y dos meses después en el Congreso de los Diputados, el Ministro contestaba a sendas preguntas formulada por miembros del grupo socialista relativas a la paralización de las obras de la línea. En las dos cámaras las respuestas eran idénticas, si bien en el Congreso de la Diputados se había explayado algo más en su intervención. Tras resumir de un modo casi telegráfico el contenido de los principales estudios e informes que se habían realizado hasta la fecha sobre el Baeza-Utiel, el ministro informaba a los interpelantes que el valor del coste de las obras que quedaban por ejecutar del trazado ascendía a 4.500 millones de pesetas, o sea, casi se habían duplicado respecto a las previsiones que acababa de hacer la consultora EYSER. Ese coste era muy similar al del establecimiento de la doble vía en el tramo de Despeñaperros, cifrado entre 5.000 y 6.000 millones de pesetas, que el Ministerio estaba barajando como solución más apropiada para superar el cuello de botella que suponía este angosto desfiladero, convirtiéndose tal mejora en una alternativa mucho más plausible que la conclusión de las obras de la línea Baeza-Utiel.

Por otra parte, el Ministro indicaba que el trazado del Baeza-Utiel presentaba dos enormes dificultades derivadas de sus fuertes pendientes y de sus extensas curvas, lo cual limitaba la velocidad de los trenes y, a efectos de tiempo, incrementaba en más de 100 kilómetros la distancia real de la línea. En vista de lo anterior, consideraba más oportuno apostar por potenciar la carretera nacional 322 como mejor medio de incrementar los niveles de desarrollo económico y social de la zona. La renuncia al ferrocarril, en todo caso, no había que contemplarla como algo negativo. Al contrario, era muy normal en Europa occidental, según afirmaba, proceder a la clausura de aquellas líneas muy deficitarias y no justificables desde el punto de vista económico. Visto de ese modo, resultaba obvio que el gobierno no tenía ningún interés en continuar las obras de una línea en la que, según aseguraba el Ministro, la inversión necesaria para ponerla en marcha absorbería por si sola tres anualidades de lo que el Ministerio tenía presupuestado para nuevas líneas.

El único compromiso que adquiría el Ministro era el de trabajar conjuntamente con las corporaciones locales para actualizar el estudio sobre el ferrocarril "con toda seriedad y todo rigor", como dando a entender que los estudios anteriores carecían de esos requisitos, y a reconsiderar "la posibilidad o no de poner en marcha esta línea". La comisión prometida se creó de inmediato, pero lo más importante no era eso, sino que una vez más desde el gobierno de la nación se eludía cualquier pronunciamiento taxativo sobre el futuro del ferrocarril. Era el mismo juego calculado que habían practicado todos los gobiernos desde 1964: negarse a la apertura del ferrocarril con la coartada de que se necesitaban nuevos estudios sobre su viabilidad económica, como si el resto de la red ferroviaria española fuera rentable y no precisara de similares estudios. En tiempos democráticos, no obstante, entraba en juego una nueva variable en esa ceremonia de la confusión. Se derivada de la posibilidad real de ganar o perder adeptos políticos y, en suma, votos en las elecciones, en razón del pronunciamiento en uno u otro sentido.

Sabedores de esa debilidad propia de quien no se atreve a tomar una decisión, como le ocurría al gobierno de turno y al partido en el que se sustentaba, el grupo parlamentario socialista en su estudiada estrategia por desgastar rápidamente al ejecutivo, volvió a interpelar al Ministro en la Comisión de transportes y c comunicaciones del Congreso de los Diputados a mediados de 1979. En este caso los socialistas, por boca de un diputado manchego, querían conocer de primera mano los resultados a los que había llegado la última de las comisiones que se había creado sobre el ferrocarril a mediados de 1978, 
en la que, como criticaban, se había dado participación a los últimos presidentes no democráticos de las Diputaciones provinciales de Albacete y Jaén, algo que resultaba completamente anacrónico. Al Ministro de Transportes no le quedaba más remedio que reconocer que no se había producido ningún avance en los trabajos de aquella comisión, entre otras cosas porque tras haber pasado un año desde su creación, aun no se había reunido sus miembros ni una sola vez. Eso ya denotaba el verdadero interés del gobierno por esta línea, a pesar de lo cual la máxima autoridad política en la materia señalaba que aun no se había producido ningún pronunciamiento sobre "este difícil y delicado tema". En el colmo del cinismo político, Sánchez Terán aseguraba, inmediatamente después de autocalificarse sin ningún pudor como un "hombre experto en temas ferroviarios", que "en un cierto momento será un ferrocarril que habrá que hacer". Eso sí, no podía predecir cuándo ni en qué condiciones.

Una vez más, a mediados de 1980, el asunto regresó al Senado, ahora como interpelación conjunta de los senadores socialistas jiennenses, albacetenses y valencianos, que esgrimiendo los conocidos argumentos tradicionales que habían dado origen al ferrocarril, pedían al gobierno que se comprometiera a finalizar las obras en el más breve plazo de tiempo posible, arbitrando los recursos necesarios para ello ${ }^{6}$. No valía seguir alegando que los problemas técnicos y financieros condicionaban la definitiva terminación de las obras, decía el texto de la interpelación, porque eso resultaba "incongruente con la solidaridad interregional y el equilibrio armónico en el desarrollo de los pueblos", máxime en este caso en el que la zona afectada presentaba problemas de paro obrero muy preocupantes que de algún modo podía contribuir a paliar la reanudación de las obras del ferrocarril.

\section{UNA CRUEL Y CRUDA REALIDAD}

Por muchas preguntas que se habían hecho y contestaciones que se habían dado, en ningún se quisieron hacer públicas, ni por el partido en el gobierno ni por el principal partido de la oposición, las verdaderas razones que se oponían a la apertura de la línea Baeza-Utiel. Los representantes provinciales de ambas formaciones políticas estamos convencidos de que las conocían perfectamente pero jamás quisieron exponerlas públicamente con toda su crudeza por miedo a perder sus cada vez más debilitados "graneros" de votos. Porque lo cierto y verdad es que el hinterland al que se refería el informe de las Cámaras de comercio en la segunda mitad de los años sesenta, lejos de mejorar en su situación demográfica y estado socioeconómico, había empeorado de una forma considerable hasta constituir una auténtica "bolsa de pobreza" de la que rehuía cualquier medio de transporte público que aspirara no ya a ser mínimamente rentable, sino simplemente a no convertirse en un foco permanente de ruina para las arcas estatales.

Desde el punto de vista demográfico toda la zona se conformaba como un verdadero desierto humano. La tendencia regresiva de la población que ya se advertía en 1965, había desembocado en una auténtica tragedia demográfica de dimensiones extraordinarias (Araque Jiménez, 1989; Fernández Santamaría, 1990). Comparando los datos de aquel Padrón con el de 1986, podía comprobarse que el conjunto de los municipios del hinterland, excluida la ciudad de Albacete, habían perdido entre esas dos fechas más de 54.000 habitantes, lo que equivalía al $22 \%$ de la población con la que contaban en 1965.Únicamente el municipio de Úbeda, de los 64 términos contabilizados, había ganado población. En cambio 5 municipios habían perdido más de la mitad de sus habitantes, y eran abundantes los que habían reducido sus efectivos entre el 50 y el 75 \% de los empadronados en 1965.

Semejante debacle demográfica no era imputable solamente a las escasas expectativas de empleo, motivo recurrente a la hora de justificar el éxodo rural de ese período histórico, sino que se debía también a otro tipo de causas estructurales que muchas veces pesaron más que las propiamente laborales a la hora de emprender el camino de la emigración definitiva. Podríamos referirnos a muchas de ellas pero basta con citar el secular aislamiento físico que padecían muchos municipios y limitaba la movilidad de sus vecinos, o la pertinaz carencia de servicios elementales de todo tipo (escolares, sanitarios, asistenciales, etc.), que hacían realmente penosa la vida en esas localidades. Sea como fuere lo cierto es que el nivel poblacional resultaba crítico para el establecimiento de una línea de ferrocarril que aspirara al transporte de pasajeros, so pena que se tuviera en cuenta la solidaridad interregional que reclamaban los miembros del grupo socialista a los que antes nos referíamos.

6 Boletín Oficial de las Cortes Generales. Senado. 16 de mayo de 1980. 
No eran mucho más halagüeñas las expectativas si la línea se contemplaba desde el punto de vista del transporte de mercancías. Se asistía en toda la zona, en ese momento de cambio de la década de los setenta a la de los ochenta, a una profunda crisis de los cultivos que conformaban la conocida trilogía mediterránea: cereal, vid y olivar, cuya dominancia superficial continuaba siendo apabullante. Los tres seguían cultivándose mayoritariamente en secano, como antaño, y mostraban idénticos signos de debilidad productiva. La plena apertura de la economía española al exterior había acabado convirtiéndolos a los tres en poco competitivos frente a los que podían importarse libremente de Europa o del resto del mundo. Eso era particularmente evidente en el caso del cereal que se producía en las grandes llanuras europeas. Los casos del vino y del aceite eran diferentes, pues en este caso su decadencia no se debía tanto a su debilidad productiva como a la incapacidad para competir en el mercado por falta de una mínima calidad en ambos caldos. Por tanto, muy poco podía esperar el ferrocarril de la movilización de estas mercancías agrarias.

Tampoco podía esperar nada la línea Baeza-Utiel de la producción de carne o de madera, otros dos recursos muy abundantes en la zona. Los ganaderos, a efectos de comercialización, seguían manejándose con la misma actitud individualista que los había caracterizado históricamente, o sea, vendiendo el ganado vivo en el mismo lugar de los montes en el que pastaba. Hasta allí llegaban los camiones de los tratantes levantinos a cargar la mercancía, cuyo precio se ajustaba sin ningún tipo de criterio ni referencia. De esta forma tan desorganizada era muy difícil que el ferrocarril pudiera beneficiarse del transporte de los productos ganaderos ni de que los empresarios del sector se beneficiaran del ferrocarril. Lo peor de todo, en cualquier caso, es que no existía ninguna voluntad de cambiar este estado de cosas por parte del colectivo, pues existían mecanismos y ayudas públicas suficientes para organizar mejor la producción y proceder a la transformación centralizada de la carne y otros derivados de la actividad pecuaria.

En lo tocante a la madera, transformada en su totalidad en traviesas para el ferrocarril, la mayor serrería de elaboración se hallaba en la cabecera del Guadalquivir, en el paraje de Vadillo Castril, a considerable distancia del trazado, y con el obstáculo insalvable de la Sierra de Cazorla de por medio. Por esa razón, Explotaciones Forestales de RENFE, la división encargada, casi en régimen de monopolio, de la extracción y transformación de este recurso, desde que se instaló en estas sierras en la inmediata posguerra, procuró dotarse de una flota cada vez más numerosas de camiones para el traslado de las traviesas hasta las distintas estaciones ferroviarias desde las cuales se producía la distribución de las piezas por toda la red. Pero eso no es todo. Cuando a mediados de los años sesenta se decidió la construcción de una serrería más moderna y eficiente que la de Vadillo Castril, en ningún momento se pensó en situarla en las proximidades de la línea Baeza-Utiel. Seguramente ese hubiera sido otro buen argumento a favor de la línea. Pero no, se optó por su emplazamiento en las proximidades del nudo ferroviario de Linares-Baeza, prueba palpable de que las máximas autoridades ferroviarias del país no tenían ningún interés en este ferrocarril, del que alejaban hasta sus propias instalaciones fabriles.

La producción de mineral, que con tan buenos indicios de futuro se había presentado dos décadas antes, no dio, ni mucho menos, los resultados esperados. Es más, casi toda la actividad minera de la provincia, incluida la del que fuera floreciente distrito Linares-La Carolina, había desaparecido a comienzos de los años ochenta. Las condiciones de explotación de las vetas de minerales, cada vez más profundas, hacían muy poco rentable, cuando no ruinosa, su extracción, por lo que uno tras otros todos los pozos mineros con actividad habían ido clausurándose. Al mismo tiempo, los concesionarios renunciaban a los permisos de explotación que se les habían concedido y aun no habían puesto en marcha. En este caso también se había notado, y mucho, la fuerte competencia internacional derivada del abaratamiento de los costes de transportes. España podía adquirir la mayor parte de los minerales que precisaba en las principales zonas productoras del mundo a unos precios muy inferiores a los que regían en nuestro país, por lo que no valía la pena seguir manteniendo vida la actividad extractiva.

En resumidas cuentas, ninguna de las previsiones formuladas respecto a la viabilidad de la línea se había cumplido. Tras la constatación de esta dura realidad, solo era necesaria la aparición de una mano ejecutora que pusiera fin definitivamente, sin ambages de ningún tipo, a la línea Baeza-Utiel.

\section{ABANDONO DEFINITIVO DE LA LÍNEA Y ENAJENACIÓN DE SUS INSTALACIONES}

La oportunidad se presentó poco después de la llegada al gobierno del PSOE en octubre de 1982. La posición política que había mantenido este partido tanto en el Congreso como en el Senado respecto al ferrocarril Baeza-Utiel, dio un giro de ciento ochenta grados a partir de su acceso al poder. En el súm- 
mum de las contradicciones, un acuerdo del Consejo de Ministros de principios de 1984, al tiempo que aprobaba el contrato-programa entre RENFE y el Estado para el periodo 1984-1986 -que implicaba el cierre de más de 3.000 kilómetros de líneas férreas en todo el país, esto es, casi la cuarta parte de la red ferroviaria en manos de RENFE-, disponía que se adoptaran las disposiciones o resoluciones precisas para abandonar definitivamente la construcción del ferrocarril Baeza-Utiel, "procediendo a la enajenación de las instalaciones y a la reversión de los terrenos correspondientes". O sea, todo lo contrario a lo que el grupo socialista había preconizado hasta unos pocos días antes. No era comprensible desde ningún punto de vista un cambio de rumbo tan radical en un partido que hasta entonces había dado muestras de cierta coherencia interna y seriedad a la hora de reclamar el ferrocarril. Ahora, puestas las cartas boca arriba, la sociedad jiennense y albacetense podía comprobar hasta qué punto habían sido víctimas de una auténtica farsa de tintes maquiavélicos. Porque la situación real de la línea de ferrocarril y de la zona por la que ésta atravesaba era obvio que debía conocerla perfectamente el "aparato" de ese partido. Y si no la conocía estaba claro que sus dirigentes eran unos verdaderos irresponsables, pues a nadie escapaba la inminencia de su acceso al gobierno de la nación. A pesar de ello, en una actitud completamente cínica, no habían dejado ni un solo momento de sembrar esperanzas entre su potencial electorado en tierras de Jaén y Albacete.

Sorprendentemente desde que se conoció tan fatal desenlace nadie inquirió al gobierno ni movió un solo dedo para que se revocara semejante acuerdo del Consejo de Ministros. La actitud reivindicativa que habían mostrado durante años las fuerzas vivas de Jaén y Albacete, por arte de birlibirloque devino de la noche a la mañana en una quietud desconcertante y en una ausencia insultante de cualquier asomo de crítica a esta injusta medida. Ante semejante atonía de la población, y completamente desintegrada la oposición política, el gobierno socialista, mediante otro acuerdo del Consejo de Ministros de julio de 1988, venía a desarrollar el anterior de 1984, señalando en esta ocasión el procedimiento a seguir para la enajenación de las instalaciones de la línea y la reversión de los terrenos a sus legítimos propietarios. Más de seis décadas después de su anuncio, por tanto, quedaba definitivamente arrumbado el proyecto ferroviario en el que tantos miles de millones de pesetas se habían despilfarrado y en el que tantas energías humanas se habían malgastado.

Si insolidaria era esta decisión política, máxime procediendo de donde procedía, no menos grave era el cierre de otras líneas que afectaban total o parcialmente a la provincia, como la de Linares-Puente Genil -excepto el tramo entre Espelúy y Jaén-, o la de Vadollano-Los Salidos. Con ello se daba un paso de gigante en el proceso de desmantelamiento ferroviario de la provincia de Jaén, iniciado algún tiempo antes con el cierre de todos los ferrocarriles de vía estrecha y de la amplia red tranviaria urbana e interurbana que atendía a núcleos de población tan importantes como Linares, Úbeda o Baeza; desmantelamiento del que todavía hoy, cuando comprobamos las propuestas de nuevos trazados ferroviarios, no nos hemos lamentado suficientemente en tierras jiennenses. Por eso nos parece absurdo que se renuncie a una infraestructura ya construida como la del tranvía de la ciudad Jaén y, una vez más, los dirigentes políticos no tenga la altura de miras que se les supone para llegar a acuerdos que redunden en beneficio de una sociedad hastiada de tanta incompetencia y personalismo.

\section{REFERENCIAS}

Araque Jiménez, E. (1989). La Sierra de Segura: crisis y posibilidades de futuro de una comarca de montaña andaluza. Sevilla: Publicaciones de la Junta de Andalucía.

Araque Jiménez, E. y Gallego Simón, V. J. (2007). La Asamblea Magna Provincial de 1925. Una oportunidad perdida para el desarrollo de la provincia de Jaén, en F. Rodríguez Martínez (Coord.): Desarrollo regional y territorio. Nuevos planteamientos y perspectivas (Comunicaciones) (pp. 51-68). Granada: Instituto de Desarrollo Regional.

Arnal Almendros, F. (1983). El paisaje agrario de Beas de Segura: su estado actual y su evolución, en VI Coloquio de Geografía. Actas. (pp. 299-304).Palma de Mallorca: Asociación de Geógrafos Españoles,

Banco Internacional de Reconstrucción y Fomento (1962). Informe-resumen del Banco Mundial sobre la economía española. Bilbao: Banco de Vizcaya Ellacuría.

Cabezas, O. (2005). Indalecio Prieto, socialista y español. Madrid: Algaba Edic. 
Cámara Oficial de Comercio e Industria provincial: su actuación en la Asamblea Magna Provincial en defensa del Proyecto general de comunicaciones en relación con la Provincia de Jaén (1925). Jaén: Imprenta Morales.

Cámara Oficial de Comercio e Industria (s. f.). El ferrocarril Baeza-Albacete. Informe elevado por las Cámaras de Comercio de Jaén y Albacete a la comisión de trabajo creada para el estudio técnico y económico del citado ferrocarril (OM 7-1-67). Jaén: Publicaciones de la Cámara Oficial de Comercio e Industria.

Casado, F. y González, J. (1984). Revisión de los proyectos de ferrocarril no realizados en la provincia de Albacete, en Congreso de Historia de Albacete. Vol. IV. Edad contemporánea (pp. 367-393. Albacete: Instituto de Estudios Albacetenses,

Cebrián Abellán, F. (2011). Los ferrocarriles olvidados. Reconversión y reinvención como instrumentos de revitalización recreativa y turística: el Baeza-Utiel a su paso por la provincia de Albacete. Cuadernos de Turismo, (27), 205-226.

CESP (Consejo Económico Sindical Provincial (1966). Estructura y posibilidades de desarrollo de la comarca de La Loma. Redactado por su Gabinete Técnico. Jaén: Original mecanografiado.

Coello, F. (1855). Proyecto de las líneas generales de navegación y de ferro-carriles en la Península española. Madrid: Imprenta de Tomás Nuñez.

Comín, F. et alter (1998). 150 años de historia de los ferrocarriles españoles. Madrid. Fundación de los Ferrocarriles Españoles. 2 Vols.

Comisaría del Plan de Desarrollo (1963). Condiciones técnicas y económicas de la continuación de los trabajos de construcción de las nuevas líneas: Madrid-Burgos, Baeza-Albacete, El Ferrol-Gijón. Madrid: Original mecanografiado.

Cuéllar Villar, D. (2003). Los transportes en el sureste andaluz (1850-1950): economía, empresas y territorio. Madrid: Fundación de los Ferrocarriles Españoles.

Escuela Técnica Superior de Ingenieros de Caminos, Canales y Puertos (1985). Inventario histórico de los puentes de Andalucía: provincia de Jaén. En línea http://infodigital.opandalucia.es/bvial/ $\underline{\text { handle/10326/873 }}$

EYSER (1978). Estudio técnico-económico de viabilidad del F.C. Baeza-Albacete. Síntesis del estudio. Sevilla: Original mecanografiado.

Fernández Santamaría, F. (1990). La población de un área de montaña de la provincia de Albacete: evolución reciente y características. Ensayos. Revista de la Facultad de Educación de Albacete, (4), 113-137.

Hernández Armenteros, S. (1999). El crecimiento económico en una región atrasada, Jaén, 1850-1930. Jaén: Instituto de Estudios Giennenses.

Ministerio de Obras Públicas (1968). Estudio económico y técnico sobre el ferrocarril Baeza-Utiel. Madrid: Secretaría General Técnica. Servicio de Publicaciones.

Ortega Campos, P. (1973). 16 años de Plan Jaén. Evaluación social. Jaén: Publicaciones de la Cámara Oficial de Comercio e Industria.

Puig, I. (1960). El Plan Jaén. Descripción de lo que es y será la provincia de Jaén. Barcelona: Ifiba.

Santos Ganges, L. (2007). Ferrocarril y estructura urbana: argumentos y trasfondo del desvío de la línea férrea en Albacete, un asunto de centralidad urbanística, en F. Polo Muriel (comp.): Jornadas de historia ferroviaria. 150 años de ferrocarriles en Albacete (1855-2005) (pp. 107-119).Albacete: Ayuntamiento de Albacete,

Vidal Raich, E. (1994). El mapa de comunicaciones de Francisco Coello (1855). Boletín de la Asociación de Geógrafos Españoles, (19), 105-112.

VV.AA (1927). El Ferrocarril de Baeza a Utiel. Fundamentos técnicos y económicos en que las fuerzas vivas de Albacete apoyan la petición hecho al Gobierno para que el proyecto ferrocarril de Baeza a empalmar con el de Cuenca a Utiel pase por esta ciudad. Albacete: Librería Papelería Talleres Minerva. 